\title{
Shaking Table Model Test and Numerical Modeling for Tunnels Traversing Faultage
}

\author{
Yang Bo ${ }^{1, *}$, Zheng Yingren ${ }^{1,2}$, Lai $\mathrm{Jie}^{1,4}$, Liu yun ${ }^{3}$ and Li Xiudi ${ }^{1}$ \\ ${ }^{1}$ Department of Civil Engineering, Logistical Engineering University, Chongqing 401311, China; ${ }^{2}$ Chongqing Key La- \\ boratory of Geomechanics \& Geoenvironment Protection, Chongqing 401311, China; ${ }^{3}$ Chongqing Jiaotong University, \\ Chongqing 400074, China; ${ }^{4}$ Chongqing Engineering and Technology Research Center of Geological Hazard Prevention \\ and Treatment, Chongqing 400041, China
}

\begin{abstract}
To reveal the response and damage mechanism of a tunnel across through the fracture zone under earthquake, a shaking table model test and numerical analysis were introduced, where the scale of the numerical simulation and the model test was 1:1. The tunnel acceleration response and the crack, development process, strain response characteristics and dynamic stress distribution of lining were investigated. The results show that the tunnel lining will be subjected to large tension and compressive stress, when its tensile strength is insufficient, tension fracture would generate in the bottom of the arch or near both sides of the arch foot, so reinforced concrete lining should be adopted in order to improve its ability to bear the tensile failure; the acceleration response of lining increases with the increase of input seismic acceleration; dynamic earth pressure response is more intense on both sides of the surrounding rock. This research can serve as a reference for the seismic design of the tunnel.
\end{abstract}

Keywords: Acceleration response, dynamic earth pressure, fracture, fracture zone, shaking table model test.

\section{INTRODUCTION}

In the past few years, seismic hazards have occurred frequently [1-3]. After the earthquakes in Hanshin, Japan, in Chi-Chi, Taiwan and the huge one in Wenchuan, Chinese engineering technicians have drawn great attention in seismic design. Although tunnels are of high anti-seismic property, those traversing fault zones are intensively damaged due to the poor condition of surrounding rocks and the peculiarity of transitive soft and hard rocks. The damages to the tunnels in the fault zone generally happen at the openings of the tunnels and the areas where fault crushes and where the soft/hard rock contacts. At present, the domestic and overseas scholars are studying the seismic failure mechanism, anti-seismic designing and seism resistance but mostly in 3 ways---seism prototype measurement, analogue experiment and theoretical analysis and values calculation. Among them, Chao Han and Daosheng Ling [4], adopting theoretical analysis, numerical modeling and model test, have studied the responding of pipe tunnels under heavy quakes and their designing methods; Chunlei Xin [5] and Chuan He [6] have carried out dynamic mock-up of the tunnels traversing fault zone and have obtained the lining dynamic response regularity and the distribution of inner force; Yingren Zheng and Qiang Xiao [7-8] have probed into the analysis methods on the location, mechanism of the damage and the stability to the loess tunnels by studying the dynamics of such tunnels; Zhengzheng Wang [9] has established the static/dynamic force conjoint analysis modeling and researched the damage reaction characteristics of the tunnels under high intensity fracturing; Lin Fang [10], with shaking tables, has compared the differences response regularities between ordinary tunnels and those in fault zones and has studied the influences of the fracturing to the seismic wave propagation.

Some progress has been made to the researches on dynamics of the fault tunnels and some helpful results have been obtained, but there still are not many dynamic experiments and numerical modeling, especially on dynamic damage mechanism, that needs further studies. On account of such status, this article will describe the large-scale shaking table experiments, discuss and verify with numerical modeling the damage mechanism and dynamic responses of the tunnels traversing faultage and will provide the results for tunnel design references.

\section{OVERVIEW OF SHAKING TABLE MODEL TEST}

\subsection{The Basic Information of the Test Model}

The shaking table test was carried with the 3D electrohydraulic servo driving earthquake simulator owned by the earthquake simulating open laboratory of the Institute of Engineering Mechanics, China Earthquake Administration, which was of a $5 \mathrm{~m} \times 5 \mathrm{~m}$ worktable, maximum load $2.5 \times 10^{4} \mathrm{~kg}$, maximum displacement in $\mathrm{X} / \mathrm{Y}$ directions $100 \mathrm{~mm}$ and $Z$ direction $50 \mathrm{~mm}$, maximum speed $50 \mathrm{~cm} / \mathrm{s}$, maximum acceleration in $\mathrm{X} / \mathrm{Y}$ directions $1.5 \mathrm{~g}$ and $\mathrm{Z}$ direction $0.7 \mathrm{~g}$, operating frequency range $0.5-50.0 \mathrm{~Hz}$. The test chamber was $3.5 \mathrm{~m}(\mathrm{~L}) \times 1.5 \mathrm{~m}(\mathrm{~W}) \times 1.8 \mathrm{~m}(\mathrm{H})$. The test model consisted of 7 tunnel pipes of $0.245 \mathrm{~m}$ in height, $0.3 \mathrm{~m}$ in width and 0,5m in length each. See Fig. (1). 


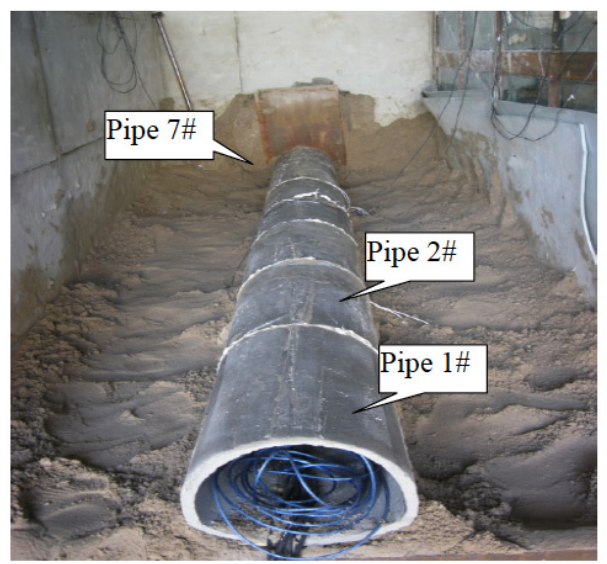

(a) Test pipe tunnel model jointing

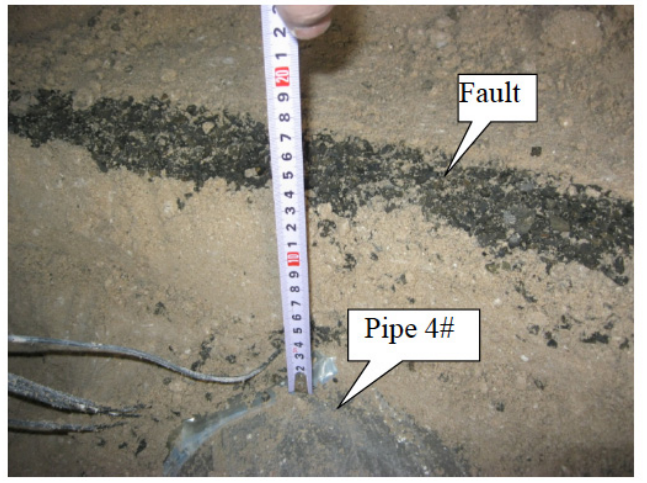

(b) Top view

Fig. (1). Tunnel shaking table test model.

\subsection{Test on Similarity Ratio}

This test was emphasized on the damage mechanism of the tunnels traversing faultage therefore it did not refer to any specified project and the ratio between the test model and the numerical modeling was $1: 1$. For application, a 20 times magnified prototype was assumed for analysis with the gravity similarity law and the dimensional method and density, acceleration and length was selected as basic controlling quantities in which $S_{\rho}=1, S_{a}=1, S_{l}=20$, and, other physical quantities were educed with the $\pi$ theorem. In elastic stage, dynamic analysis needed the condition of $S_{E} S_{l}^{-1} S_{\rho}^{-1}=S_{a}=S_{g}$ but in considering the gravity effect (the elasticity-gravity similarity law), there came an issue on material design as the gravity acceleration was fixed by the shaking table, i.e. $S_{a}=S_{g}=1$, while $S_{E}=S_{l} S_{\rho}$. The problem was solved with thanks to Gao Lin [11] who had concluded in his research that the crucial factor of a civil construction in the stage close to the damage was the strength of the material not the modulus the effect of which could be neglected and, also, that the strength of the material referred to the internal friction angle and the cohesion played less important role. Hence by the gravity similarity law, with the similarities of material density and strength and not much the same similarity of elastic modulus, the similarity of the model was shown in Table $\mathbf{1}$.

\subsection{Material Proportions and Monitors Lay-Out}

The lining of the test model was cast in place with concrete $\mathrm{C} 25$ and the mechanically pre-tested surrounding rock was composed with standard sand, gypsum powder, talcum powder, glycerol, concrete and water in the ration of $70.2 \%: 11.8 \%: 7.2 \%: 0.03 \%: 0.57 \%: 10.2 \%$. Jointing fault was $3 \mathrm{~cm}$ wide, loosely filled with medium sand. The lining had been directly shear tested and uniaxial tested with a cubic sample of $10 \mathrm{~cm}^{3}$ to get the shear strength $c$ and $\varphi$ test value which would be converted into design values. The physical-mechanical parameters of the lining, fault and surrounding rock were shown in Table 2.

The tunnel model contained 7 pipe sections outside-toinside and 2 faults were set at the junctions between pipe 2\# and pipe $3 \#$ and between pipe $5 \#$ and $6 \#$. The fault strike was $45^{\circ}$ off the tunnel axis with $90^{\circ}$ inclination. In order to get the response regularity in earthquakes, earth pressure cells, accelerometers, strain foils and other sensors were placed in the cross sections of pipe $3 \#, 4 \#$ and $5 \#$, as in Fig. (2) and Fig. (3).

(1) The placement of accelerometers and earth pressure cells

Accelerometers were mainly installed on the worktable of the shaking table and pipe $3 \#, 4 \#$ and $5 \# .3$ of the accelerometers were on the worktable for $\mathrm{X}, \mathrm{Y}$ and $\mathrm{Z}$ directions respectively and earth pressure cells also for the earth pressure of the lining. The layout was as in Fig. (2), in which the $\mathrm{Y}$ axis was the horizontal direction, $\mathrm{X}$ for vertical direction and $\mathrm{Z}$ for the axial direction.

Table 1. The model main similarity constant.

\begin{tabular}{|c|c|c|c|c|c|}
\hline Ph. Qty & Resemblance & Similarity Constant & Ph. Qty & Resemblance & Similarity Constant \\
\hline \hline Density & $S_{\rho}$ & 1 & Inn. Fiction Angle & $S_{\varphi}=1$ & 1 \\
\hline Length & $S_{l}$ & Cohesion & $S_{c}=S_{\rho} S_{l}$ & $S_{t}=S_{l}^{0.5}$ \\
\hline Elastic Modulus & $S_{E}=S_{\rho} S_{l}$ & 20 & Time & $S_{f}=1 / S_{t}$ & 4.472 \\
\hline Strain & $S_{\varepsilon}=1$ & 1 & FR & $S_{v}=S_{E}^{-0.5} S_{\rho}^{-0.5}$ & 0.223 \\
\hline Acceleration & $S_{a}=S_{E} /\left(S_{l} S_{\rho}\right)$ & 1 & Speed & 0.223 \\
\hline
\end{tabular}


Table 2. Physical-mechanical parameters of model slope.

\begin{tabular}{|c|c|c|c|c|c|c|}
\hline Mat. & $\begin{array}{c}\text { Spec. } \mathbf{W} \\
/\left(\mathbf{k N} \cdot \mathbf{m}^{-3}\right)\end{array}$ & Elastic Mod/MPa & Poisson Ratio & $\begin{array}{c}\text { Cohesion } \\
/ \mathbf{k P a}\end{array}$ & $\begin{array}{c}\text { Tensile } \\
/ \mathbf{k P a}\end{array}$ \\
\hline \hline Surrounding & 21.0 & 40 & 0.36 & 40 & 27 & 10.5 \\
\hline Faults & 19.5 & 10 & 0.38 & 2 & 26 \\
\hline Lining & 25.0 & $28 \times 10^{3}$ & $0.20^{*}$ & 2130 & 51.6 & 1300 \\
\hline
\end{tabular}

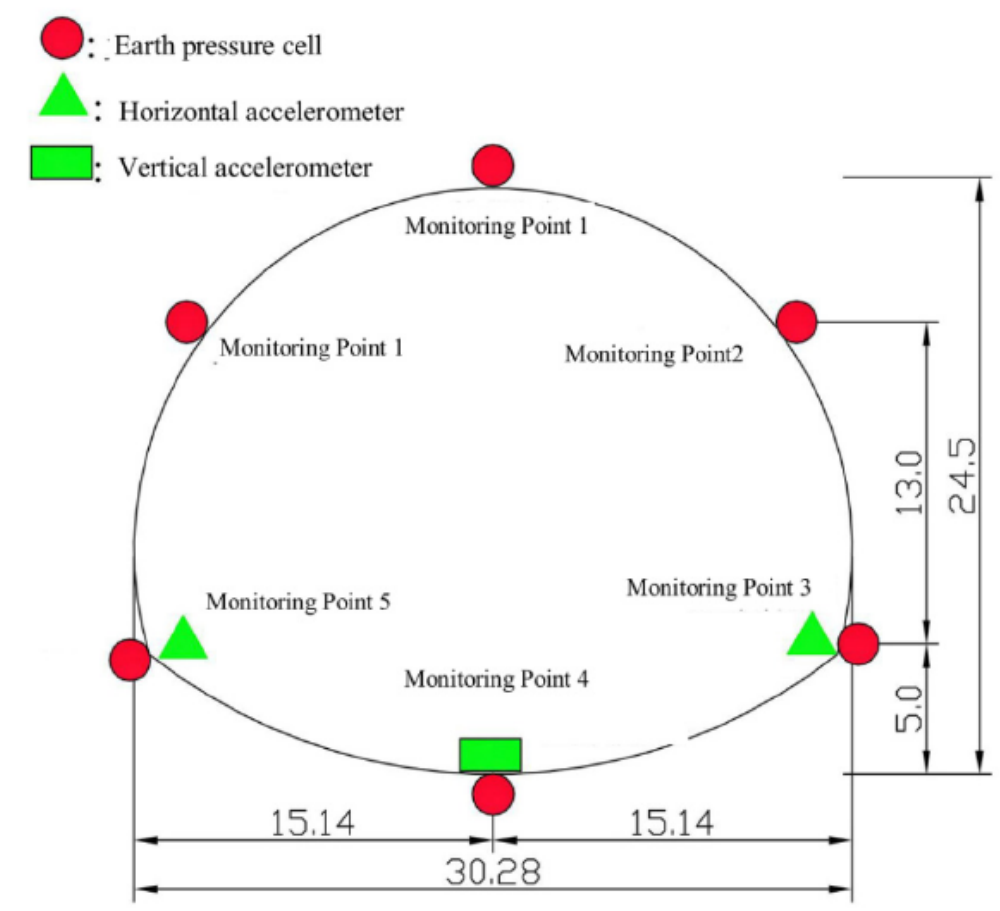

Fig. (2). Layout of accelerometers (cm).

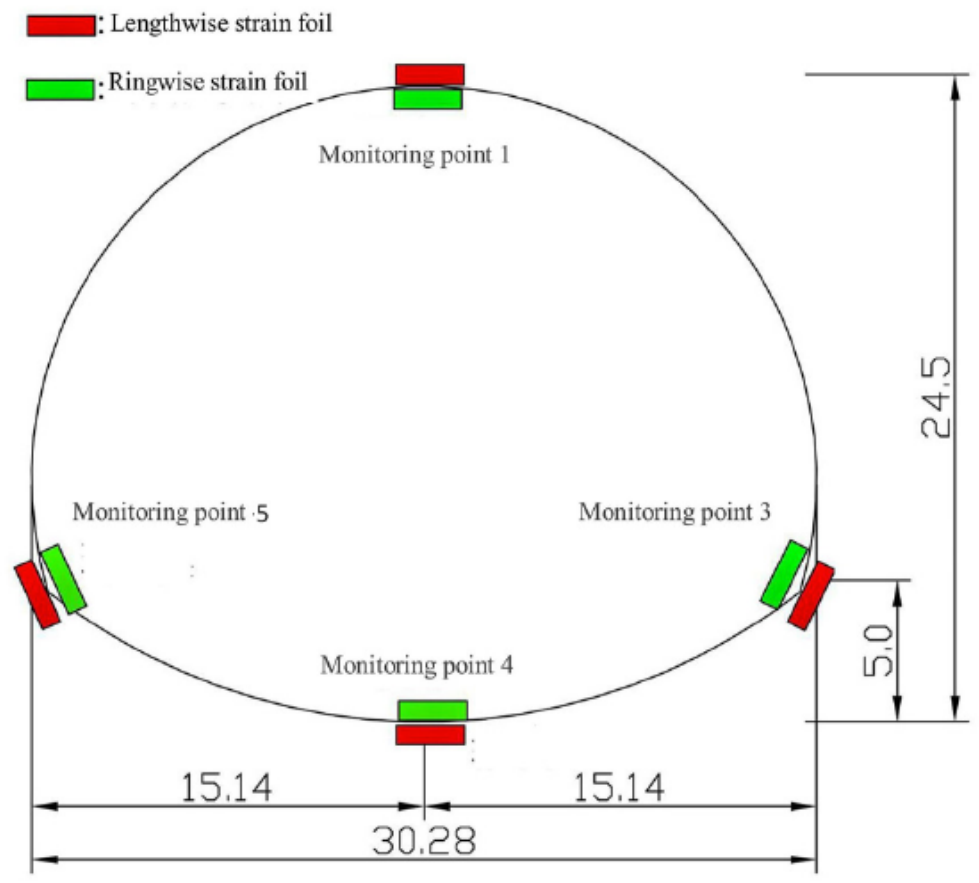

Fig. (3). Layout of strain foil (cm). 
Table 3. Information of input seismic waves.

\begin{tabular}{|c|c|c|c|c|c|}
\hline Test Conditions & Seismic Wave Type & Peak acceleration (g) & Test Conditions & Seismic Wave Type & Peak acceleration (g) \\
\hline 1 & Wenchuan & $0.2 \mathrm{~g} \mathrm{Y}$ & 11 & Wenchuan & $0.7 \mathrm{~g} \mathrm{YZ}$ \\
\hline 2 & Wenchuan & $0.2 \mathrm{~g} \mathrm{YZ}$ & 12 & Wenchuan & $0.7 \mathrm{~g} \mathrm{XYZ}$ \\
\hline 3 & Wenchuan & $0.3 \mathrm{~g} \mathrm{Y}$ & 13 & Wenchuan & $0.8 \mathrm{~g} \mathrm{YZ}$ \\
\hline 4 & Wenchuan & $0.3 \mathrm{~g} \mathrm{YZ}$ & 14 & Wenchuan & $0.8 \mathrm{~g} X Y Z$ 向 \\
\hline 5 & Wenchuan & $0.4 \mathrm{~g} \mathrm{Y}$ & 15 & Wenchuan & $0.9 \mathrm{~g} \mathrm{YZ}$ \\
\hline 6 & Wenchuan & $0.4 \mathrm{~g} \mathrm{YZ}$ & 16 & Wenchuan & $1.0 \mathrm{~g} \mathrm{YZ}$ \\
\hline 7 & Wenchuan & $0.5 \mathrm{~g} \mathrm{YZ}$ & 17 & Wenchuan & $0.8 \mathrm{~g} \mathrm{YZ}$ \\
\hline 8 & Wenchuan & $0.5 \mathrm{~g} \mathrm{XYZ}$ & 18 & Wenchuan & $0.9 \mathrm{~g}$ XYZ向 \\
\hline 9 & Wenchuan & $0.6 \mathrm{~g} \mathrm{YZ}$ & 19 & Wenchuan & 1.0g XYZ向 \\
\hline 10 & Wenchuan & $0.6 \mathrm{~g} \mathrm{XYZ}$ & & & \\
\hline
\end{tabular}

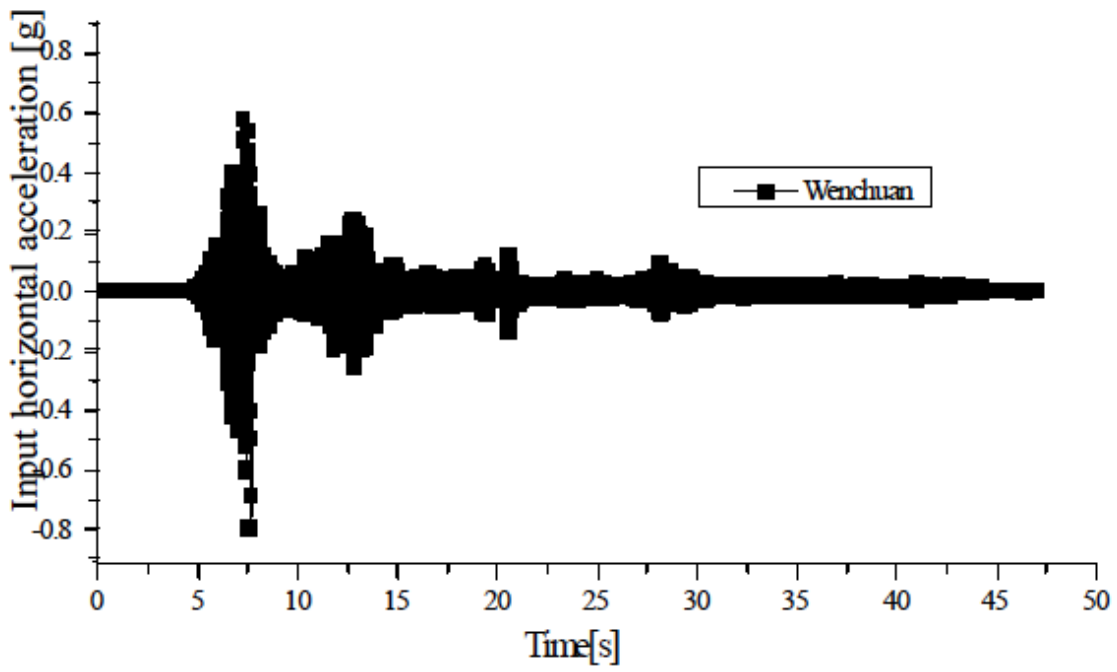

Fig. (4). Input horizontal seismic acceleration curve in the model test (Peak value is $0.8 \mathrm{~g}$ ).

\section{(2) The placement of strain foils}

Strain foils were mounted on the worktable and inside the pipe 3\#, 4\# and 5\#, see Fig. (3).

\subsection{Information of Seismic Waves Input}

To eliminate the influence of the walls of the model case in the test, thick cushion courses were laid on inside walls of the case. The Wolong Wenchuan seismic waves from $0.2 \mathrm{~g}$ gradually to $1.0 \mathrm{~g}$ had been adopted in the test for excitation. The condition under the wave inputs was recorded in Table 3. According to the statistic data showing that the ratio of vertical and horizontal peak ground accelerations was $1 / 3$ $2 / 3$ [12], actual seismic waves recorded by monitoring stations were input in the same mode in the test in 2 and then 3 directions with the ratio of $1 / 3$ of the vertical $(Z)$ and horizontal (Y) peak accelerations. 19 inputs had been conducted and Fig. (4) shows the horizontal acceleration when $0.8 \mathrm{~g}$ seismic wave was input to the test model.

\section{NUMERICAL MODELING}

Numerical modeling calculation could only be made in part due to the huge size of the model and the limited calculating capacity of the computer. Thence, pipe $5 \#$ had been taken as an example for the numerical simulation analysis

FLAC $^{3 \mathrm{D}}$ [13] was applied for the numerical modeling with physical unit simulating faults and lining. In order to reflect the real situation, a ratio of 1:1 was used in modeling as the test model. The calculating parameters were introduced from the test and the mesh generation was as in Fig. (5). The mesh boundary was open to prevent the seismic waves from reflecting against the boundary and to simulate the situation of an infinite field of an earthquake effecting to the tunnel. Damping was set partially with the soil mass damping factor 0.157 and lining, 0.126 . For a better effect of the simulation, displacements, accelerations, dynamic earth pressures and the positions and serial numbers of the monitoring points in the modeling simulation were set in the same as those in the test. The seismic waves input in the simula- 
tion were the Wenchuan waves with peak acceleration $0.8 \mathrm{~g}$ in the directions of Y and Z. To save time but not affect the calculation results, the input of the main energy segments was intercepted from the shaking table test that was 18.0s, from $3.0 \mathrm{~s}$ to $21.0 \mathrm{~s}$, as the simulation of seismic load.

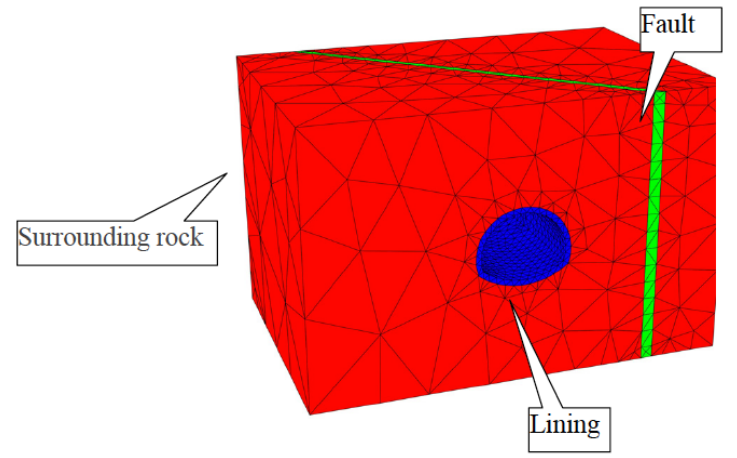

Fig. (5). Numerical simulation model.

\section{ANALYSIS OF DYNAMIC RESPONSE AND DAM- AGE MECHANISM OF TUNNELS}

\subsection{Damage to the Model}

Following measures had been taken mainly to record the damage to the tunnel model: (1) video cameras mounted inside the tunnel pipes to record the damaging procedure in some areas under 19 conditions of seismic wave inputs; (2) naked-eye observation on the status of all tunnel pipes after the experiment. Camera 1 had recorded the situation at the top of pipe 3\# where no fissure had been found throughout loading. Camera 2 had recorded the damage shown in Fig. (6) at the joint between pipe $4 \#$ and 5\#. When seismic wave peak acceleration lower than $0.4 \mathrm{~g}$, there was no fissure at the bottom of the tunnel pipe, (see Fig. (6) (a)); and when the value went to $0.5 \mathrm{~g}$, fissures occurred in the lining of pipe $4 \#$ and 5\# (see Fig. (6) (b)) and they got wider as the value went higher; after the peak acceleration reached $0.8 \mathrm{~g}$, the fissures got to $2 \mathrm{~mm}$ at the largest but no collapse (see Fig. (6) (c)) had happened.

After the experiment, fissures of different degrees could be seen in all pipes. The situation in pipe $3 \#, 4 \#$ and $5 \#$ was recorded in Table 4 and Fig. (7).

Table 4. Statistical table of pipe fracture.

\begin{tabular}{|c|l|}
\hline Pipe \# & \multicolumn{1}{|c|}{ Fissure appearance } \\
\hline \hline $3 \#$ & Perforative fissures on both sides, inner fissures at the bottom \\
\hline $4 \#$ & $\begin{array}{l}\text { Fissures appear at the bottom of the arch ring,arch springing } \\
\text { on both sides and inner up-left; a perforative fissure on the } \\
\text { left side }\end{array}$ \\
\hline $5 \#$ & $\begin{array}{l}\text { Fissure appear at the bottom, on both sides close to arch } \\
\text { springing, inner top; a perforative fissure on left side }\end{array}$ \\
\hline
\end{tabular}

Fig. (8) shows the damage state in a cross section of pipe $5 \#$. Different from being affected by static force, the reciprocation of an earthquake brought push and pull to the lining and the tensile strength of concrete was comparatively lower and more easily damaged. In the damage state diagram of lining, it shows that the damage to the lining has been that of tension mainly at the arch springing, the bottom and in the top area that has been similar to the test except the positions where have been a little bit lower than in the test. Learning from the test and modeling simulation, the lining of tunnels through earthquake areas should be of high tensile strength with ferroconcrete.

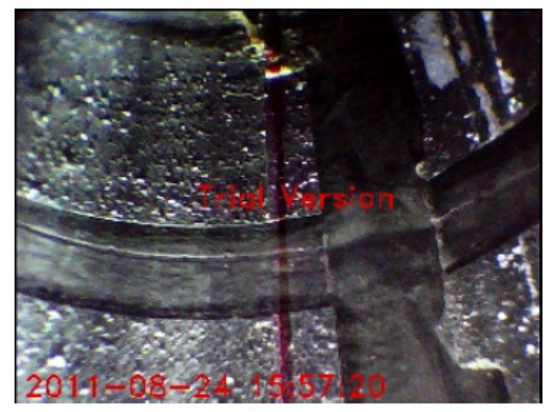

(a) No fissure is found at the bottom

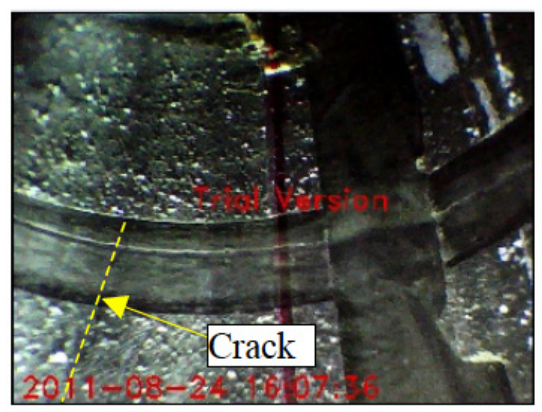

(b) Fissures occur at the bottom

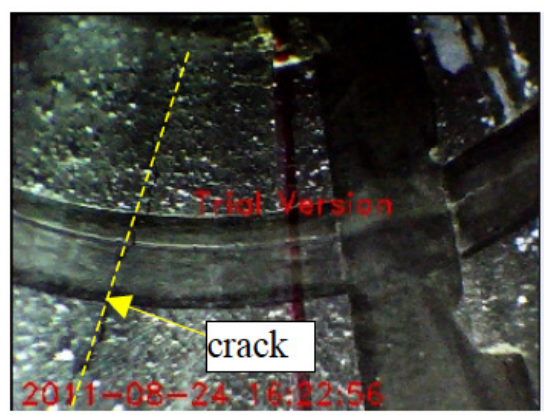

(c) Fissures at the bottom getting wider

Fig. (6). Video screenshots at the bottom of pipe $4 \#$ and $5 \#$.

\subsection{Acceleration Responses of Tunnel}

For the comparison with the numerical modeling, pipe 5\# in the test is taken as the example for the analysis on the acceleration responses regularity. When seismic wave peak acceleration $0.8 \mathrm{~g}$ was input in the directions $\mathrm{Y}$ and $\mathrm{X}$, the oscillogram of response detected at the monitoring point in the pipe as in Fig. (9) indicated the great acceleration magnification effect of the lining. Table $\mathbf{5}$ shows the acceleration responses differing at the different monitoring points indicating that the horizontal acceleration in the middle of the lining has been magnified greatly. 


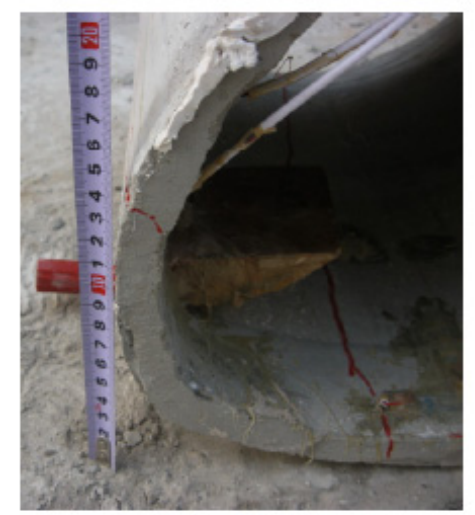

(a) Fissures in pipe $3 \#$ at the left and the bottom

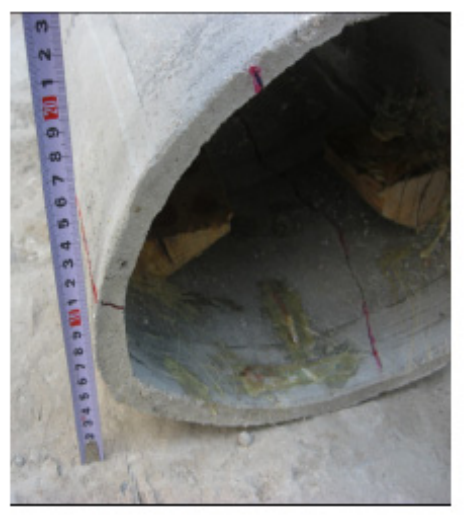

(c) Fissures in pipe $4 \#$ on the left side and at the bottom

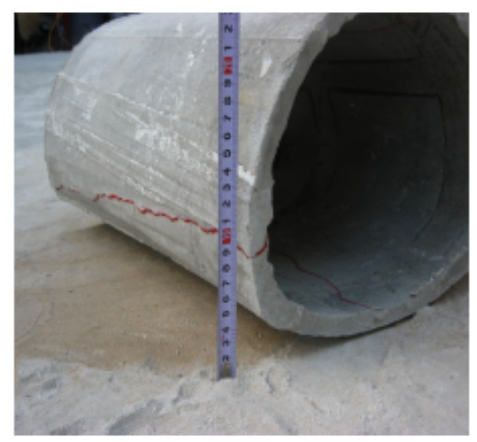

(e) Fissures in pipe $5 \#$ on the left side

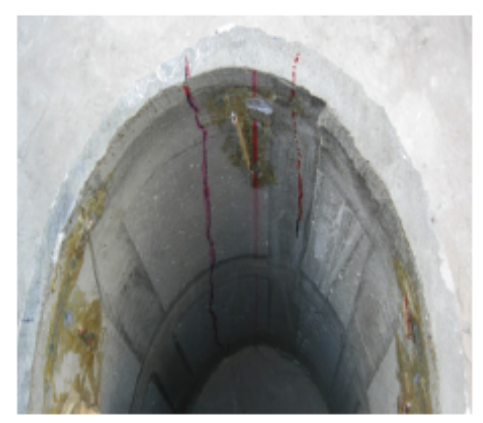

(g) Fissures in pipe 5\# at the top

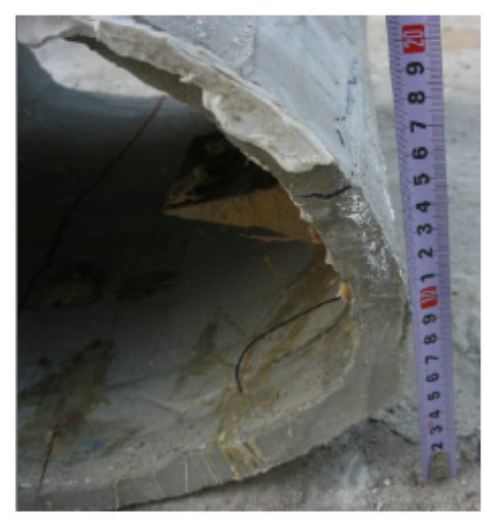

(b) Fissures in pipe $3 \#$ on the right side

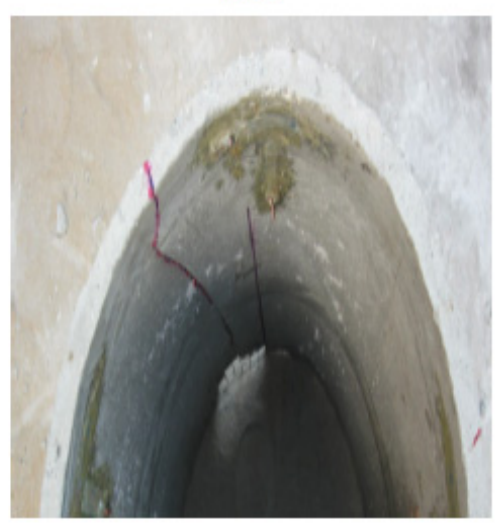

(d) Fissures in pipe 4\# at the top and on the right side

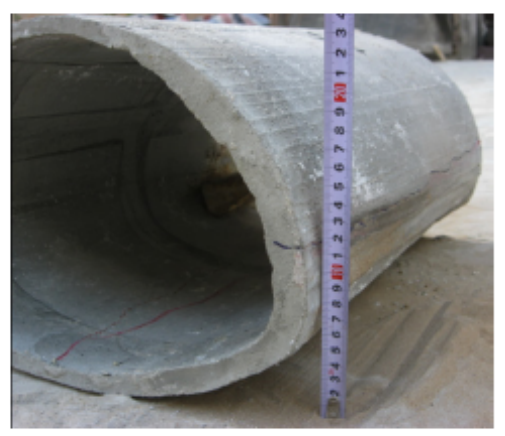

(f) Fissures in pipe 5\# on the right side

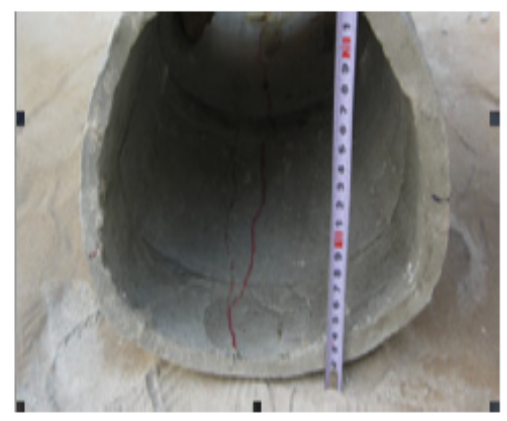

(h) Fissures in pipe $5 \#$ at the bottom

Fig. (7). Fissure locations of different pipes. 


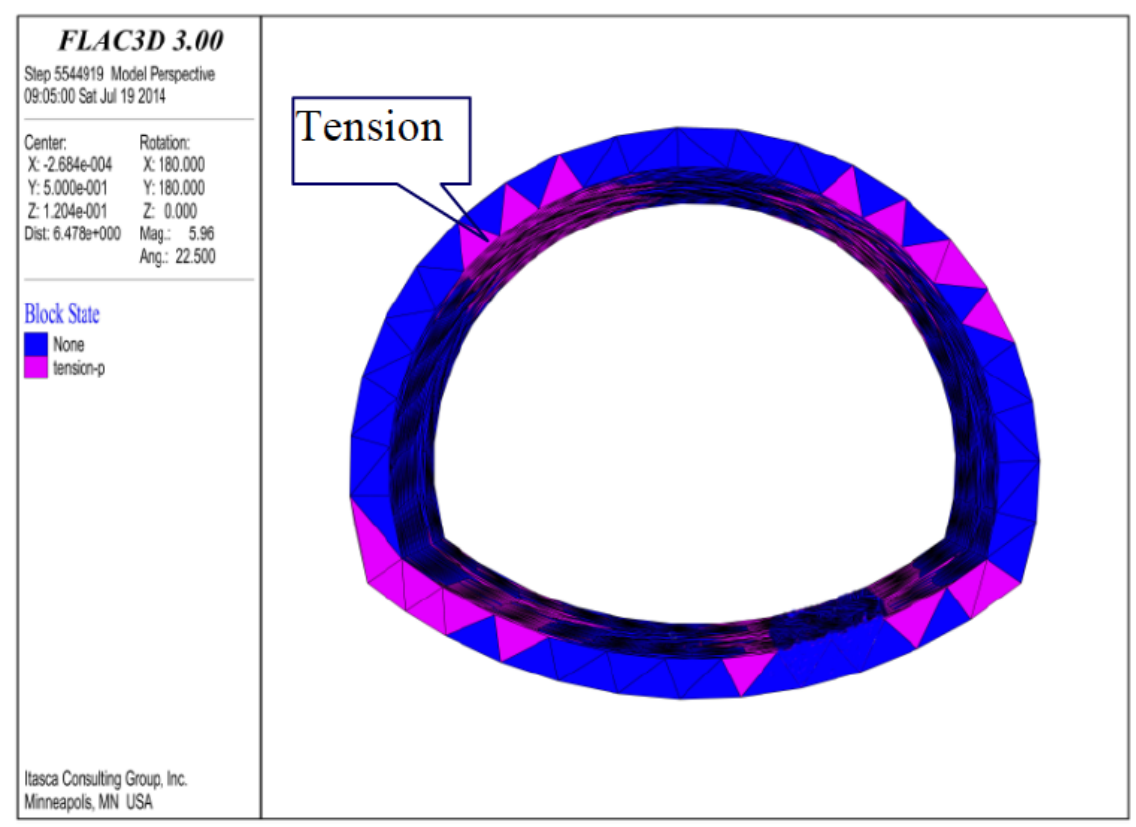

Fig. (8). Damage state diagram of lining.

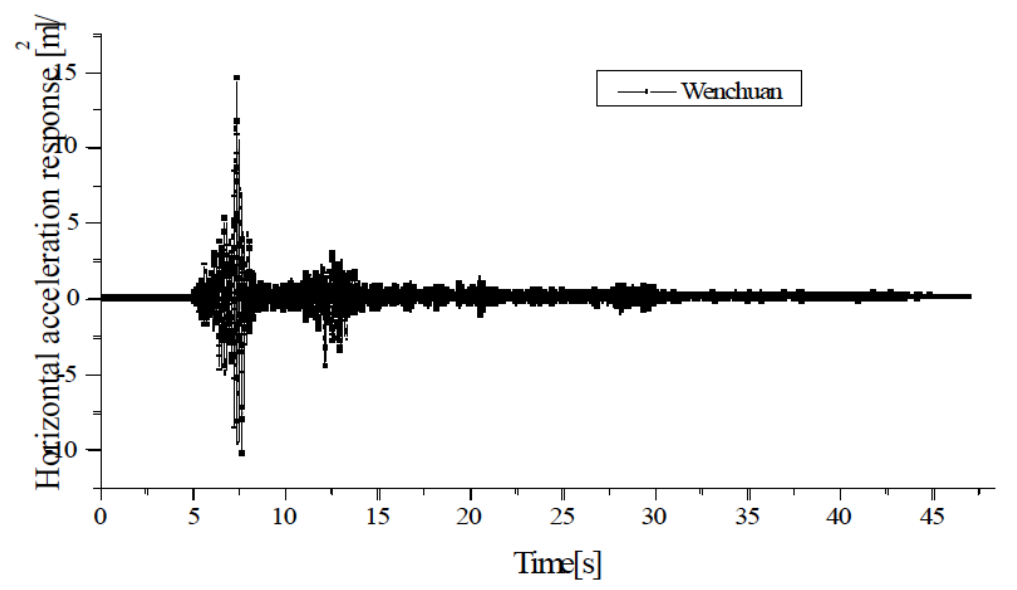

(a) Test

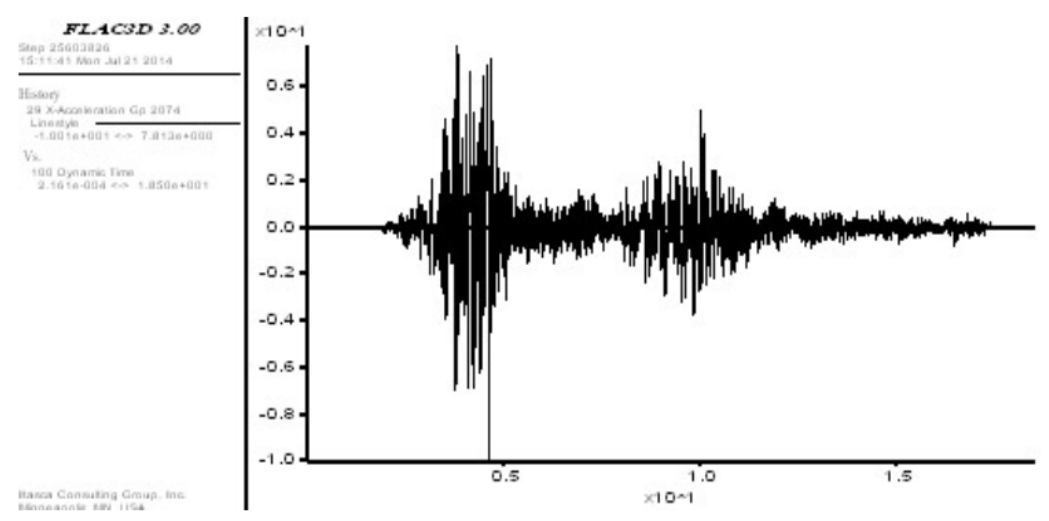

(b) Modeling

Fig. (9). Time-history curve of horizontal acceleration at monitoring point 3. 
Table 5. Statistics of horizontal acceleration of pipe $5 \#$.

\begin{tabular}{|c|c|c|c|}
\hline Type & Left bottom & Right bottom & Center of bottom \\
\hline \hline Acceleration direction & Horizontal & Horizontal & $3.1 \mathrm{~m} / \mathrm{s}^{2}$ \\
\hline Input & $8 \mathrm{~m} / \mathrm{s}^{2}$ & $8 \mathrm{~m} / \mathrm{s}^{2}$ & $3.8 \mathrm{~m} / \mathrm{s}^{2}$ \\
\hline Test response & $9 \mathrm{~m} / \mathrm{s}^{2}$ & $14.6 \mathrm{~m} / \mathrm{s}^{2}$ & $4.3 \mathrm{~m} / \mathrm{s}^{2}$ \\
\hline Modeling response & $8.8 \mathrm{~m} / \mathrm{s}^{2}$ & $11.1 \mathrm{~m} / \mathrm{s}^{2}$ & 1.22 \\
\hline Test magnification & 1.13 & 1.83 & 1.05 \\
\hline Modeling magnification & 1.1 & 1.39 & \\
\hline
\end{tabular}

(a) Test
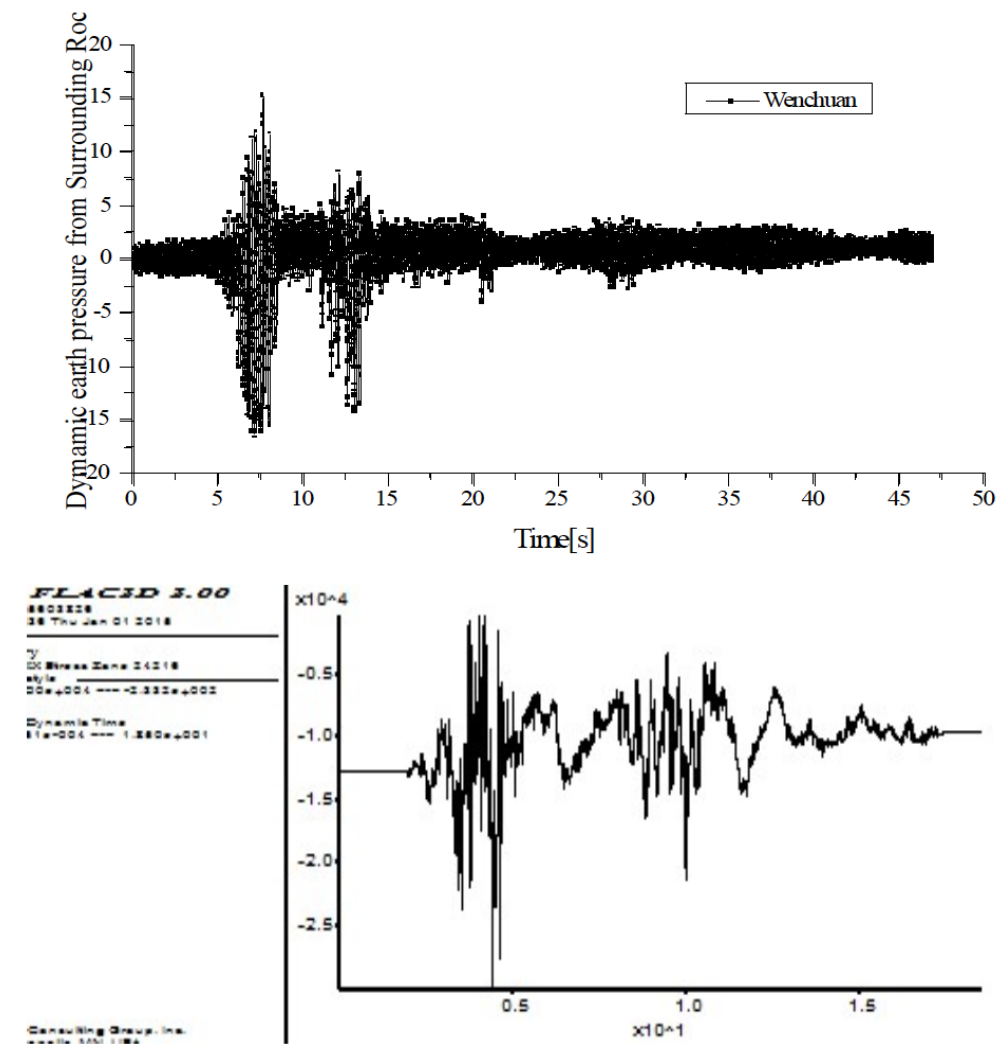

(b) Numerical modeling

Fig. (10). Time-history curve of dymamic earth pressure from Surrounding Rocks at monitoring point 3.

\subsection{Earth Pressures from Surrounding Rocks}

It should be noted that by experiment, seismic amplitude was gradually increased and there existed the storage effect on the responses of displacement and pile body driving force which had been deducted in this article.

Fig. (10) is the oscillogram of the dynamic earth pressure at monitoring point 3 when the Wenchuan seismic wave $0.8 \mathrm{~g}$ ( $\mathrm{Y}$ and $\mathrm{Z}$ ) has been input. Since the seismic wave peak time $3.0 \mathrm{~s}-21.0 \mathrm{~s}$ by test was adopted for the numerical modeling, the result $4.78 \mathrm{~s}$ was tantamount to $7.78 \mathrm{~s}$ that was close to the dynamic earth pressure peak time detected at 7.6s. That meant the dynamic earth pressure peak time of the tunnel was essentially the same as that in modeling when the seis- mic wave was input and the peak acceleration could quickly bring the peak dynamic earth pressure to the tunnel.

Fig. (11) shows the peak value of the dynamic earth pressures at 6 monitoring points and in numerical modeling when different seismic waves have been input. It could be concluded that (1) for a monitoring point, earth pressure increased by the input of higher peak acceleration; (2) the highest value of earth pressure appeared at monitoring point 3 where it was the arch springing. The regularity of dynamic earth pressure in numerical modeling was similar to that in the test except the values at monitoring point 3 which were higher than those in the test. In general, dynamic earth pressure was higher on both sides than on the top and at the bottom. 


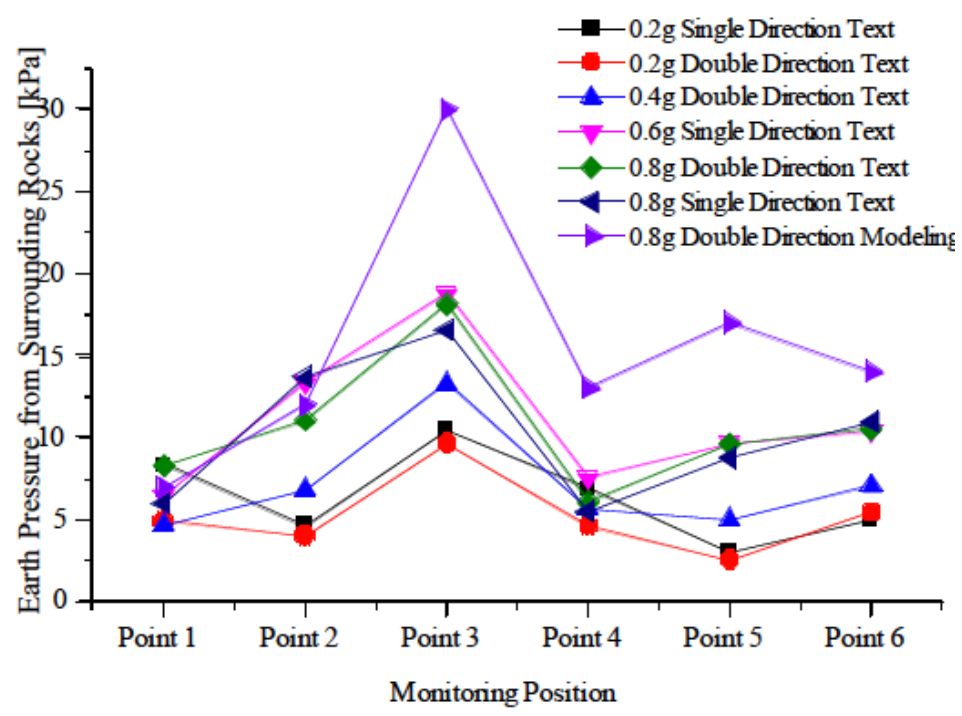

Fig. (11). Peak dynamic earth pressure of monitoring points under different earthquake waves.

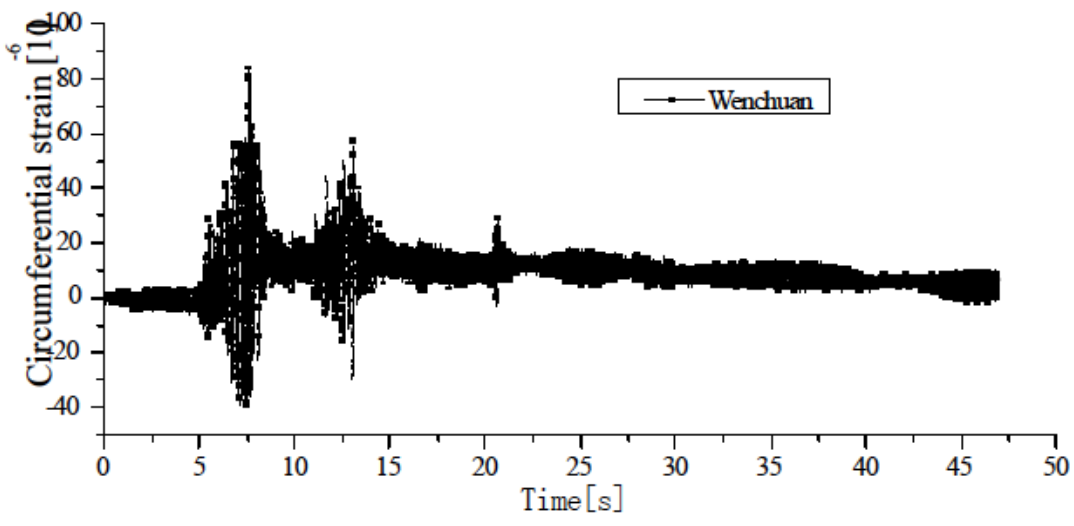

(a) Time-history curve of circumferential strain at point 1 (Test)

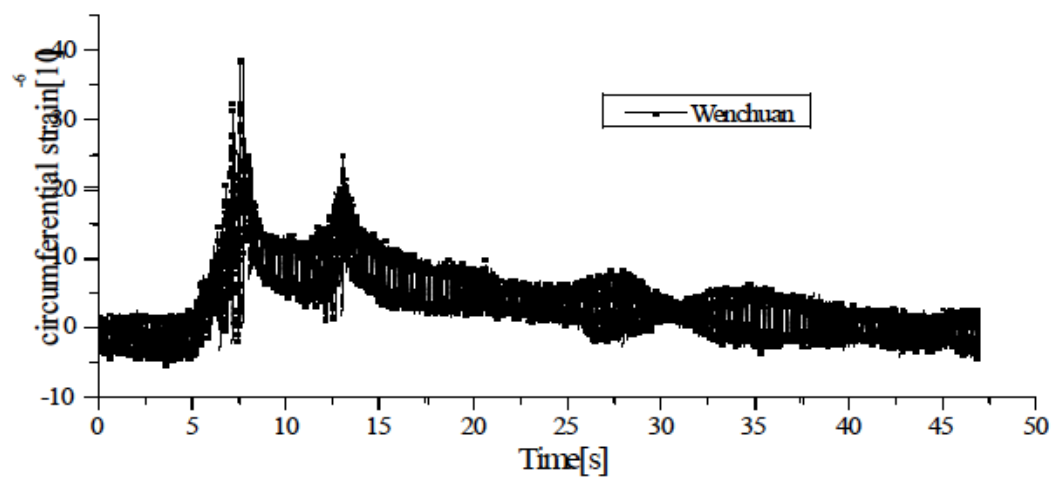

Fig. (12). Time-history curve of circumferential strain in pipe 5\# (Test).

\subsection{Strain of Tunnel}

8 strain foils (4 circumferential and 4 lengthways) were mounted inside pipe $5 \#$ to detect the tension and compression strains inside the pipe. The placement was as in Fig. (3). During the experiment, lengthways strain foil at monitoring point 1,3 and 4 was destroyed so the analysis could only be done with circumferential strain foils. Fig. (12) is the Timehistory curve of the strain in pipe $5 \#$ which shows that the peak time is $7.65 \mathrm{~s}$, basically the same as the peak time of dynamic earth pressure and seismic wave input. The peak strains in test and modeling were shown in Table $\mathbf{6}$ which indicated (1) inner circumferential strain was tensile strain with higher value appearing at point 1 , the top, and apparently increasing with the seismic acceleration; (2) strain lengthways was lower than that circumferential; (3) peak strain value in modeling was tensile and close to the test value. 
Table 6. Statistics of strains under different seismic waves $(\mu \varepsilon)$.

\begin{tabular}{|c|c|c|c|c|c|c|}
\hline & \multicolumn{3}{|c|}{ Model test } & Numerical modeling \\
\hline Pos. & $\mathbf{0 . 2 g}$ 1D & $\mathbf{0 . 2 g}$ 2D & $\mathbf{0 . 4 g}$ 2D & $\mathbf{0 . 6 g}$ 3D & 0.8g 2D & 0.8g 2D \\
\hline \hline Point 1 & 35.573 & 35.245 & 52.765 & 96.811 & 80.44 & 56 \\
\hline Point 3 & 34.219 & 18.915 & 18 & 28.496 & 38.466 & 41.359 \\
\hline Point 4 & 11.324 & 7 & 15.674 & 32.558 & 29.173 & 34 \\
\hline Point 5 & 27.654 & 20.228 & 23 & 23 & 44 \\
\hline
\end{tabular}

\section{CONCLUSION}

The shaking table test has revealed the dynamic response and the damage mechanism of the tunnels traversing faultage and with numerical modeling simulation, the similarities have been found in the results of both and it can be concluded as:

(1) In the shaking table test, fissures mostly appear around arch springing of both sides, both sides of the top and the bottom. Either in test or in modeling, the fissures are tension fractures but no lining fissure found in the position where the fault passing across is probably because of the small scope of the fault.

(2) The test shows that the seismic acceleration can be magnified in both horizontal and vertical directions and dynamic earth pressure rises with the increase of seismic acceleration and also higher on both sides of the lining. Strain on the inner side of the lining is that of tension and strain circumferential is higher than that lengthways.

(3) This numerical modeling was only on a portion of the testing model so the calculation accuracy was of some limit. Even the result of modeling is generally in accordance with that in the test, that basically reflects the response regularity and damage mechanism of the tunnel traversing faultage, but there are still some differences in numerical values. Therefore, it is quite necessary to have numerical modeling to improve the cognitive level in designing complex and anti-seismic tunnels.

\section{CONFLICT OF INTEREST}

The authors confirm that this article content has no conflict of interest.

\section{ACKNOWLEDGEMENTS}

This work is supported by the national key research and development program (973) project (2011CB013600,
2011CB710603); National Natural Science Foundation of China (NSFC) (51378496); Chongqing Natural Science Foundation for Academician of special Project (CSTC2013jcyjys0002).

\section{REFERENCES}

[1] K. Kawamata, "Seismic design of underground structure," Tokyo: Kajima Press, pp. 43-60, 1994.

[2] Z. Z. Wang, and B. Gao, "Seismic response analysis of the tunnel with accumulated damage and crack effect in shaking table test," In: The 14th World Conference on Earthquake Engineering. Beijing, China, pp. 1-8, 2007.

[3] Z. Wang, "Nonlinear seismic damage response of tunnel structure across fault," Chengdu: Southwest Jiao Tong University, 2009.

[4] C. Han, "Study on the response and design method of circular tunnel under severe earthquakes," Zhejiang: Zhejiang University, 2011.

[5] C. Xin, B. Gao, J. Zhou, et al. "Shaking table tests on performances of anti-seismic and damping measures for fault-crossing tunnel structures," Chinese Journal of Geotechnical Engineering, vol. 35, no.10, pp. 1807-1815, 2013.

[6] C. He, L. Li, J. Zhang, et al. "Seismic damage mechanism of tunnels through fault zones," Chinese Journal of Geotechnical Engineering, vol. 36, no.3, pp. 427-434, 2014.

[7] Y. Zheng, Q. Xiao, J. Xin, et al. "Shaking Table Test Studies of Failure Mechanism of Unlined Loess Tunnel under Earthquake," Chinese Journal of Underground Space and Engineering, vol. 8, no.1, pp. 19-25, 2012.

[8] Q. Xiao, Y. Zheng, and H. Ye, "Stability analysis of static unlined loess tunnel," Chinese Journal of Underground Space and Engineering, vol. 6, no.12, pp. 1136-1141, 2010 .

[9] Z. Wang, "Nonlinear seismic damage response of tunnel structure across fault," Chengdu: Southwest JiaoTong University, 2007.

[10] L. Fang, S. Jiang, and Z. Lin, et al. "Shaking table model test study of tunnel through fault," Rock and Soil Mechanics, vol. 32, no.9, pp. 2709-2713, 2011.

[11] G. Lin, T. Zhu, and B. Lin, "Similarity technique for dynamic structural model test," Journal of Dalian University of Technology, vol. 40, no.1, pp. 1-8, 2000.

[12] Y. Luo, "Study on complex slopes response law under earthquake action," Chengdu: Chengdu University of Technology, 2011.

[13] Itasca Consulting Group, "Inc.. Fast Lagrangian analysis of continua in three dimensions(version 3.0), user's manual," [S.1.]: Itasca Consulting Group, Inc., 2005.

\footnotetext{
Received: May 26, 2015

Revised: July 14, 2015

Accepted: August 10, 2015

(C) Bo et al.; Licensee Bentham Open.

This is an open access article licensed under the terms of the (https://creativecommons.org/licenses/by/4.0/legalcode), which permits unrestricted, noncommercial use, distribution and reproduction in any medium, provided the work is properly cited.
} 